\title{
Urinary Tract Malformation and Infection with Hyperkalemia and Decreased Fractional Excretion of Potassium in an Infant
}

\author{
Takeshi Asano ${ }^{1,2}$, Masanori Abe ${ }^{1,2}$, Makiko Asai ${ }^{1,2}$, \\ Taiyoh Imai ${ }^{1,2}$, Mitsuhiro Kamisago ${ }^{1,2}$, Kentaroh Kuwabara, ${ }^{1,2}$, \\ Mizue Nakajima ${ }^{1,2}$, Mutsumi Murakami ${ }^{1,2}$ and Osamu Fujino ${ }^{1,2}$ \\ ${ }^{1}$ Department of Pediatrics, Nippon Medical School Graduate School of Medicine \\ ${ }^{2}$ Department of Pediatrics, Chiba-Hokusoh Hospital, Nippon Medical School
}

\begin{abstract}
We describe an uncircumcised male infant treated for urinary tract infection who exhibited multiple hormonal and electrolyte abnormalities consistent with a diagnosis of transient pseudohypoaldosteronism. Successful treatment of the urinary tract infection was accompanied by the resolution of all hormonal and electrolyte abnormalities, including hyperaldosteronemia, hyperreninemia, hyponatremia and hyperkalemia. Radiographic examination revealed marked left dilatation of the renal pelvis and hydroureter but no vesicoureteral reflux. Owing to the possibilities of future renal scarring, decreased renal function, and hypertension, evaluation of urinary tract malformation and appropriate hormonal studies should be performed in infants with urinary tract infection and hyperkalemia.
\end{abstract}

(J Nippon Med Sch 2006; 73: 289-291)

Key words: Pseudohypoaldosteronism, infant, urinary tract infection, urinary tract malformation, hypokalemia

\section{Introduction}

Numerous recent cases of renal scarring and reflux on follow-up imaging demonstrate that infant urinary tract infection is not a benign condition. Urinary tract infection in early life may also lead to compromised renal function and possibly to hypertension later in life $^{2}$. In newborns with obstructive uropathy, a syndrome has been described in which infant urinary tract infection is accompanied by elevated serum levels of aldosterone, hyponatremia and hyperkalemia and in which hormonal and electrolyte abnormalities are reversed after the infection is treated ${ }^{3}$. Here, we report on a 7-month-old male infant who exhibited pseudohypoaldosteronism with hydronephrosis and infection.

\section{Case Histories}

A male infant was admitted to our hospital at 7 months of age after 7 days of persistent vomiting despite medical treatment, including oral antibiotics. Physical examination revealed an uncircumcised penis, dehydration, and a body temperature of

Correspondence to Takeshi Asano, MD, Department of Pediatrics, Chiba-Hokusoh Hospital, Nippon Medical School,

1715 Kamakari, Inba-gun, Inba-mura, Chiba 270-1894, Japan

E-mail:VFF13540@nifty.ne.jp

Journal Website (http://www.nms.ac.jp/jnms/) 
Table 1 Laboratory findings

\begin{tabular}{|c|c|c|}
\hline Hospital Day & $1^{\text {st }}$ day & $11^{\text {th }}$ day \\
\hline $\mathrm{BUN}(\mathrm{mg} / \mathrm{d} l)$ & 31.7 & 3.7 \\
\hline $\mathrm{Cr}(\mathrm{mg} / \mathrm{d} l)$ & 0.38 & 0.10 \\
\hline $\mathrm{Na}(\mathrm{mEq} / \mathrm{L})$ & 109.0 & 140.0 \\
\hline $\mathrm{K}(\mathrm{mEq} / \mathrm{L})$ & 6.6 & 5.0 \\
\hline $\mathrm{Cl}(\mathrm{mEq} / \mathrm{L})$ & 82.0 & 104.0 \\
\hline U-Na (mEq/L) & 41.0 & 23.0 \\
\hline U-K (mEq/L) & 25.5 & 32.3 \\
\hline $\mathrm{U}-\mathrm{Cr}(\mathrm{mg} / \mathrm{d} l)$ & 29.43 & 7.07 \\
\hline FENa (\%) & 0.49 & 0.23 \\
\hline FEK (\%) & 5.00 & 9.13 \\
\hline $\mathrm{U}-\mathrm{K} / \mathrm{U}-\mathrm{Na}$ & 0.6 & 1.4 \\
\hline FEK/FENa & 10.3 & 39.3 \\
\hline Aldosterone (ng/dl) & $2,827.6$ & 43.5 \\
\hline Renin (ng/ml/hour) & 40.8 & 6.6 \\
\hline $\mathrm{NAG}(\mathrm{U} / \mathrm{L})$ & 23.6 & 1.3 \\
\hline$\beta_{2}$-microglobin(mg/L) & 165 & 97 \\
\hline Blood gas: $\quad \mathrm{pH}$ & 7.39 & 7.45 \\
\hline Bicarbonate $(\mathrm{mmol} / \mathrm{L})$ & 9.2 & 22.0 \\
\hline Base excess $(\mathrm{mmol} / \mathrm{L})$ & -13.7 & -0.3 \\
\hline
\end{tabular}

$38.0^{\circ} \mathrm{C}$. Laboratory tests showed hyponatremia and hyperkalemia (Table 1). Urinalysis indicated urinary tract infection, but culture of urine failed to identify a pathogen. Endocrine tests revealed elevated serum aldosterone levels $(2,827.6 \mathrm{ng} / \mathrm{d} l)$ and plasma renin activity $(40.8 \mathrm{ng} / \mathrm{ml} /$ hour). The infant was treated intravenously with normal saline solution and antibiotics. Subsequently, serum levels of sodium and potassium returned to the normal ranges and findings of urinalysis became normal (Table 1). Radiographic examination revealed left dilatation of the renal pelvis and hydroureter (Fig. 1), but no vesicoureteral reflux (VUR) was detected. Antibiotic prophylaxis was started at 8 months of age. At age 1 year, the infant underwent surgery for ureteral reimplantation.

\section{Discussion}

Urinary tract infection in infants causes renal scarring and can compromise future renal function. Infants with urinary tract infection are also reported to have elevated serum levels of aldosterone, hyponatremia, and hyperkalemia ${ }^{3.5}$. Here, we have reported on a 7-month-old male infant who presented with pseudohypoaldosteronism. We could not isolate a specific pathogen from urine culture,

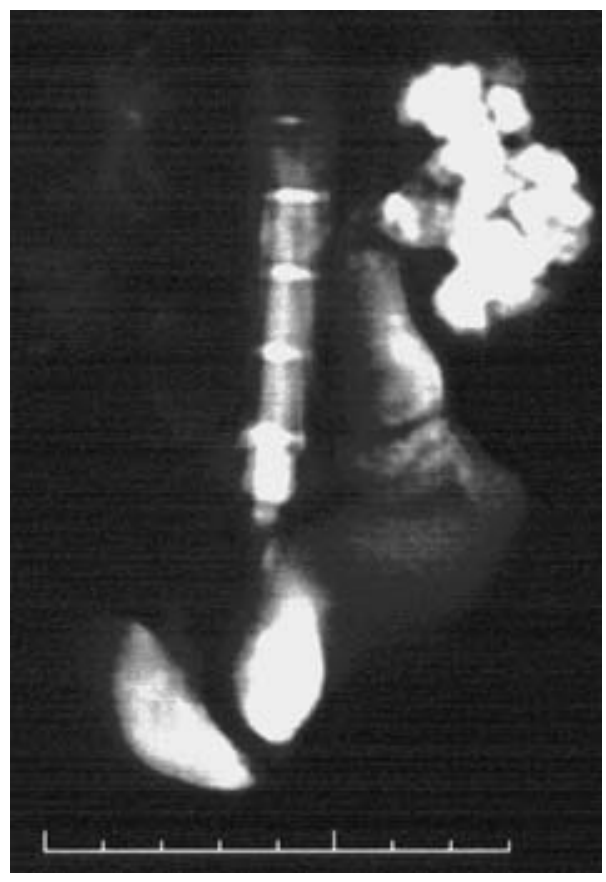

Fig. 1 Magnetic resonance urography: Marked hydroureter and marked dilatation of the pelvis of the left kidney with a thin parenchyma were noted. The thin parenchyma of the left kidney was enhanced with contrast material, but accumulation and efflux were significantly delayed compared with the right kidney.

and although he had taken antibiotics for several days before admission to our hospital, the urine still showed numerous bacteria. We thus believed that he had a urinary tract infection ${ }^{6}$, and because he also had hydronephrosis, we considered this to be a typical case of pseudohypoaldosteronism.

Our review of 60 cases of secondary pseudohypoaldosteronism previously reported shows that urinary tract infection and urinary tract anomalies are additional factors for the development of secondary pseudohypoaldosteronism, with at least one required for its development? Temporary aldosterone resistance in infants decreases the distal secretion of $\mathrm{H}^{+}$and $\mathrm{K}^{+}$, the distal absorption of $\mathrm{Na}^{+}$, and the activity of $\mathrm{Na}-\mathrm{K}$ adenosine triphosphatase ${ }^{8}$. This resistance to aldosterone is increased by urinary tract infection ${ }^{9}$ because interstitial inflammation or a bacterial toxin, either primarily or secondarily through the synthesis and release of inflammatory mediators, might cause tubular unresponsiveness to aldosterone. 
On the other hand, urinary tract obstruction might increase intrarenal pressure and the intrarenal synthesis of cytokines, and the increased intrarenal pressure and cytokine production might be responsible for the renal tubular dysfunction. Also the obstruction would lead to a reduction in renal blood flow and involve the complex reninangiotensin mechanism, resulting in elevated aldosterone levels.

In conclusion, urinary tract infection and urinary tract malformation can lead to an acute metabolic imbalance in infants with urinary tract malformation. Tract malformation should be suspected in an infant with hyperkalemia and urinary tract infection.

Acknowledgement: We thank Professor Yoshitaka Fukunaga from the Department of Pediatrics, Nippon Medical School, for critical review.

\section{References}

1. Rushton HG, Majd M, Jantausch B, Wiedermann BL, Belman AB: Renal scarring following reflux and nonreflux pyelonephlitis in children: evaluation with ${ }^{99 \mathrm{~m}}$ technetium-dimercaptosuccinic acid scintigrahy. J Urol 1992; 147: 1327-1732.

2. Goonasekea CD, Chulananda DA, Shah V, Wade AM,
Barratt TM, Dillon MJ: 15-year follow-up of rennin and blood pressure in reflux nephropathy. Lancet 1996; 347: 640-643.

3. Rodriguez-Soriano J, Vallo A, Oliveros R, Castillo G: Transient pseudohypoaldosteronism secondary to obstruction uropathy in infancy. J Pediatr 1983; 103: 375-380.

4. Pumberger W, Frigo E, Geissler W: Transient pseudohypoaldosteronism in obstructive renal disease. Eur J Pediatr Surg 1998; 8: 174-177.

5. Melzi ML, Guez S, Sersale G, et al.: Acute pyelonephritis as a cause of hyponatremia/ hyperkalemia in young infants with urinary tract malformation. Pediatr Infect Dis J 1995; 14: 56-59.

6. Vickers D, Ahmad T, Coulthead MG: Diagnosis of urinary tract infection in children: fresh urine microscopy or culture? Lancet 1991; 338: 767-770.

7. Watanabe $\mathrm{T}$ : Reversible secondary pseudohypoaldosteronism. Pediatr Nephrol 2003; 18: 486.

8. Gerigk M, Glanzmann R, Rascher W, Gnehm HE: Hyponatremia and hyperkalaemia in acute pyelonephritis without urinary tract anomalies. Eur J Pediatr 1995; 154: 582-584.

9. Caverzasio J, Rizzoli R, Dayer J-M, Bonjour J-P: Interleukin-1 decreases renal sodium reabsorption: possible mechanism of endotoxin-induced natriuresis. Am J Physiol 1987; 252 (Renal Fluid Electrolyte Physiol 21): F943-946.

(Received, July 10, 2006) (Accepted, August 10, 2006) 